\title{
The Effects and Management of Municipal Solid Waste Generation and Disposal on Human Health in Serrekunda Market (Commercial Center), Kanifing Municipality, The Gambia
}

\author{
Vincent Oyareme ${ }^{1 *}$, Eunice I. O. Osaji ${ }^{2}$, Amadou Barrow ${ }^{3}$, Alagie Bah ${ }^{4}$ \\ ${ }^{1}$ School of Agriculture \& Environmental Sciences, University of the Gambia, Kanifing, The Gambia \\ ${ }^{2}$ Department of Physical and Health Education, Faculty of Education, Delta State University, Abraka, Nigeria \\ ${ }^{3}$ School of Arts and Science, Public Health (Option), University of the Gambia, Kanifing, The Gambia \\ ${ }^{4}$ World Agroforestry, Sky Blue Plaza Bijilo Annex Layout, Banjul, The Gambia \\ Email: ${ }^{*}$ oyaremegmail.com
}

How to cite this paper: Oyareme, V., Osaji, E.I.O., Barrow, A. and Bah, A. (2021) The Effects and Management of Municipal Solid Waste Generation and Disposal on Human Health in Serrekunda Market (Commercial Center), Kanifing Municipality, The Gambia. Open Access Library Journal, 8: e7755 https://doi.org/10.4236/oalib.1107755

Received: July 13, 2021

Accepted: August 8, 2021

Published: August 11, 2021

Copyright $\odot 2021$ by author(s) and Open Access Library Inc.

This work is licensed under the Creative Commons Attribution International License (CC BY 4.0).

http://creativecommons.org/licenses/by/4.0/ (c) (i) Open Access

\begin{abstract}
In the past decades, management of waste in the form of liquid, solid and gaseous state had been the problem a lot of West African countries have been facing as well as the whole world. Management of solid waste as a major problem encountered on waste management, this is because, the solid form of most waste, can change to liquid form, from liquid into gaseous state depending on the external temperature (heat) that acts on them. Wastes are regarded as an unwanted substance, unusable materials, which have no use. The increase in Population, development and technological advancement is what brought about urbanization, which has been increasing on a fast scale recently. Rapid population growth increase in the urban area has resulted in challenges in infrastructures and many land degradation. The fast level of factory growth as well as industrialization in this community increases the standards of living which have significantly accelerated greatly in a developing country like the Gambia. Recently, increase in municipality in quantity and composition, constitute an impact in the market that affects human health. This study was carried out to analyze the effects and management of municipal solid waste generation and disposal in public on human health in Serrekunda market, to ascertain the awareness level of Serrekunda residents living close to Serrekunda market municipality and to know if the residents at Serrekunda market municipality have protective mechanisms to protect themselves against external mechanical hazards, damage caused by improper waste arrangement and management. This research is based on a descriptive survey method design. The randomly arranged sampling technique is used to obtain
\end{abstract}


a representative of 220 participants from a targeted population of males and females in Serrekunda, the research also employs simple percentage for the analysis. The highest agreed mean percentage recorded is $46.4 \%$ against disagreed mean of $3.6 \%$ on No health hazards associated with improper waste disposal that has ever affected anybody in Serrekunda, and I am not aware that improper waste disposal that causes neurological disorder had low agreed percentage response of $10 \%$ and disagree response percent of $40 \%$. It was found that majority of the respondents are not aware of the health hazards of improper waste disposal management and its effects on climate change. The statistical package (t-test) is used to test the significant level. The t-test showed insignificant difference in the critical value, hence Null Hypothesis $\left(\mathrm{H}_{\mathrm{O}}\right)$ is accepted $(\mathrm{P}>0.05)$.

\section{Subject Areas}

Environmental Sciences

\section{Keywords}

Solid Waste Materials, Solid Waste Effects on Human Health, Environmental Deterioration and Management

\section{Introduction}

In recent decades, population increase and technological advancement have been increasing in a rapid scale of urbanization. Rapid population growth in the urban, has resulted in several significant in land deterioration, challenges on infrastructure and level of municipality, fast industrial growth, factory growth and living standard in the community have accelerated solid waste production rates in developing countries like the Gambia. Nowadays, more than fifty percent $(>50 \%)$ population in the whole world lives in urban areas, fifty percent less $(<50 \%)$ lived in the rural areas, that by 2050 estimate, it will increase to sixty-six percent $(66 \%)$ or more population that will live in the urban center; the population of the world is expected to exponentially increase to two and half billion urban population dwellers, according to United Nations (2014) [1]. With regards to speed rate of growth, population increase in the urban area has proceeded to various land deterioration, infrastructure and developmental difficult tasks regarding waste municipality efficient management. The level of population increase in flourishing economy, fast urbanization growth rate, increases the standard of living greatly in this community, which has significantly accelerated in a developing country like the Gambia. According to Ma and Hipel (2016) [2], solid waste municipality increases in quantity and composition in the whole world. Wastes are unwanted, unusable materials by-products that are not voidable to human activity, also as a substance that has no use. Waste has different sources, for example domestic wastes are the type of waste generated in 
our homes and surroundings. It could be either garbage or rubbish. Garbage wastes are the kind of solid waste that can decompose easily, they are sometimes moist and they are from organic constituents; examples are fruits and vegetables. Refuse or rubbish wastes are dry form of solid waste from the inorganic constituent; examples are paper, nylon bags, shoes etc. Another source of waste is from our poultry farms known as Agricultural wastes, which are organic wastes as well because they are gotten from our birds and animals; examples are birds droppings and cow dungs. Wastes also have their sources from the markets, schools and offices as municipal solid wastes. The industrial wastes are the type of waste that have their source of generation from the industries and factories examples are plastics, electronics such as refrigerators, television sets, radios, mobile phones, fans etc. The rise of living standard in the economic development has brought about increase in the complication of waste quantity generated in the environment, while industrial diversification, provision of health care facilities has added strong quantities of hazardous waste which poses potentially severe environmental health problems. Waste is also substances which are no longer useful after the process of completion of usage with regards to its reuse and recycle approaches. It also refers to the useless byproduct activities of human that contain physically the same composition of substance when recycled. Waste materials are also those materials that people would want to dispose of even if payments are required for their disposal. The eye of the beholder depends on what constitutes waste. Although, production of waste can be in form of physical process, the way in which these wastes are created affects human psychologically. In the United States of America, waste professionals, use different terms in municipal solid waste such as sludge, sewage, rubbish and trash, sludge is a mixture of a non-flowing liquid and sewage waste is discharged from our residential environment [3] [4]. Waste management is an important element of environmental protection. The strategic ways of treatment of liquid and gaseous waste, give a wide range of answers to a distinct physical object that is not classified as rubbish. The whole approaches and method go down to reprocessing of organic waste material into valuable resources. Recent changes in our environment are very important to all households. With regards to waste disposal, it refers to the needed state of being active from inception to waste ultimate disposal. Waste collection, transportation, disposal and treatment collectively, cover the guidance, rules and regulations of waste disposal framework. Basically, there are eight methods of waste management; each is split into numerous parts in a pyramidal form. Waste Management is also seen as excellent and efficient way of managing waste. All actions carried out in waste separation into reusable resources by reusing and regulating littering to avoidance, prevention, and reduction possibly, recycling the waste to control environmental degradation and health hazards in the community and the materials put in place to ensure proper residual disposal which promotes health, personal hygienes and sanitation in the schools and the communities. Protection motivation theory (PMT), according to 
Rogers (1983) [5], is related to the perceived attitude and awareness towards the hazards waste caused through improper disposal and management among residents close to Serrekunda market municipality, perceived severity of threatened, for example offensive smell attacks generated, from the solid waste in the form of gaseous waste such as Carbon dioxide $\left(\mathrm{CO}_{2}\right)$, Chlorofluorocarbon (CFC), Sulphur dioxide $\left(\mathrm{SO}_{2}\right)$, Oxides of Nitrogen $\left(\mathrm{NO}_{\mathrm{X}}\right)$ and methane gas $\left(\mathrm{CH}_{4}\right)$ effects in the atmosphere causing climate change, leading to global warming and depletion of ozone layer. According to PMT, interpretation version in 1983 was a means of understanding. The reason while people should respond to potential threats to their health and safety. Also point towards people and factors in the environmental, both in support or loss of confidence for involving in protective behavioral effects of those resolved representatives of people cognitive reasoning. The domain reasoning's are said to be different from directly assumed connection of fear on protective response. Till now, conception is being applied vastly illustrates individuals related protective health behaviors. Protective precautionary measures, motives wearing sunscreen to prevent Skin Irritation, Cancer, Nose Mask, Hand gloves, Eye Goggle, Safety Helmet, Safety Boot etc. have received substantial empirical support by Rogers [6] and Milne et al. [7]. Protection Motivation Model, explained the components of the model and Environmental information sources, including intrapersonal factors that give individual suggestions regarding risk and vulnerability, threat to risk, and vulnerable victims witness direct observations and knowledge relates to individual's gathered knowledge may control ones perceptions of willingness to use protective measures, that will not lead to criminology act in the market environment. Regarding sources of information, Rogers itemizes two categories of information sources, as personal source of information and intrapersonal information. Prior to experiences, personal variables are put forward an idea for people to think about the vulnerable victims in waste pollution and the protective mechanism for the control and management such offensive smell threats in the market area. In Serrekunda market, the pollution rate is both the inside and the outside market metropolis. The carbonated empty canned drinks and empty plastics in addition to cellophanes contributed to the blockage of different drainage system due to poor and improper management. With respect to dividends, both the inside and outside the market environment may encourage or discourage the concerned people, to involve in attitudes that may expose them to the potential dangers or not, some of the people also think about the threat factor carefully about their concerns staying in such environment. Improper waste disposal management also affects the respiratory organs of the body due to smoke generated from it during incineration as one of its management. The perceived occurrence of market municipal solid waste will continue in the Gambia because building of recycling factory is under probability. This is because African countries most especially the Gambia don't make a sustainable plan on waste management approach for the betterment of future generation to be benefited from 
because Proper Planning Prevents Poor Performance (5P) of waste management, as such people in this market area perceived vulnerable difficulties in respiration resulting to other breathing challenges like Asthma, Bronchitis, Silicosis etc. Perceived self-efficacy response, threat appraisal process and coping appraisal process are the factors to be considered.

\section{Methods of Study}

\subsection{Description of the Area}

Serrekunda town, at the Commercial Centre (Market Municipality), has Latitude $13^{\circ} 26^{\prime} 17^{\prime \prime} \mathrm{N}$ and Longitude $16^{\circ} 40^{\prime} 41^{\prime \prime} \mathrm{W}$. The Serrekunda town is in the Gambia, it is one of the largest town, and its name was derived from the Sayer family' hence the name (Sayer Kunda). Serrekunda has population of 390,000 people, 13 $\mathrm{km}$ away from the city, Banjul. Serrekunda comprises nine different towns together, collectively form its Local Government Area. Serrekunda Town is bounded and congested with craft and motorist. It is the busiest and most commercial center of the west coast zone in the Gambia, that is, one of the largest geographically, most climatically conducive zones and most economically significant in the Gambia. Recently, Serrekunda city is serving as a meeting place for numerous activities and events. These combined approaching activities have their own economic and ecological importance of the town, that attracts more people from different areas and locations of the country, is what made Serrekunda town to be very popular in the Gambia.

\subsection{Study Design}

This research is designed based on the qualitative research approach on the effects of Solid Waste Municipality generation Disposal on human health and its management in Market Municipality. A descriptive survey research design is adopted with the use of questionnaire for the purpose of this study. According to Nachmais and Frankfort-Nachmais (2008) [8], descriptive research design is programmed to be meeting the guidance of the researcher in terms of collecting, observing, analyzing and interpreting the nature and process of the research.

\subsection{Study Population}

Study population consists of both males and females between the ages of 25 - 40 years. Two hundred and twenty (220) clients were selected in Commercial Centre (Market Municipality). There are both literate and illiterate persons, staying in research station where these wastes are improperly disposed.

\subsection{Sample and Sampling Techniques}

Systematic sampling techniques will be employ and used randomly for the purpose of this study. Two hundred and twenty (220) persons were targeted for the population that will be used for this study, to represent the total population of respondents of both male and female residents, residing in commercial centre 
(market municipality) where wastes are been disposed.

\subsection{Data Collection Tool (Research Instrument)}

The instrument used in this study is questionnaire; this questionnaire is divided into sections, namely Section A and Section B. Section A is a representative for bio-data information and section $B$ is meant for responses used in answering the research questions as: Strongly Agree (SA), Agree (A), Strongly Disagree (SD) and Disagree (D).

\subsection{Data Collection Technique}

Questions were asked from the participants in order to be able to carry out the study. In collecting the data, questionnaire was administered and interpreted in the terms and languages best understood by the participants. Accordingly, Ogbeibu (2014) [9], having known a probability confidence level (C.L) 95\% and probability sampling error $5 \%$, small letter " $\boldsymbol{n}$ " is the sample size and it is determined by the big letter " $N$ " as the total number of household wastes generated for disposal. A suitable Sample survey for collecting primary data is employed for this study; however, arranged questionnaire is used for household's municipality wastes. Observations and interviews are also employed to collect complementary data.

\subsection{Analysis of Data}

This research employs a simple statistical percent and correlation factor measurement used to characterize the respondents' responses. All analysis was computed using descriptive software of Statistical Package for Social Sciences (SPSS) to characterize analyzed data representation in the form of tables, graphs and charts.

\subsection{Validity of the Study}

Validity of the study is the degree of what a test measures and what it is designed to measure. The questionnaire was formulated by the researcher and edited by the supervisor in the department, in the school of Agriculture and Environmental Sciences (SAES) and the corrections formed my final draft of the questionnaire.

\subsection{Methods of Data Analysis}

This research will employ simple percentage for the analysis of this study. The calculation used is shown below for further expression.

Percentage (\%) = Total number of outcome (N) Divided by the total of Sample (F) multiply by 100 where $\mathrm{F}=$ frequency of the response,

$\mathrm{N}=$ Number of response,

$\%=$ Percentage.

\section{Results}

This study was conducted on the effects and hazards associated with market 
municipality waste disposal and management in the Environment on human health. Data obtained was tested and analyzed from the questionnaire administered to resident in using simple percentage method. The response achieved in this study was quite okay and two hundred and twenty (220) questionnaires administered were all filled and retrieved from respondents.

\subsection{Data Analysis}

Table 1 shows all the data analysis on the effects and hazards associated with waste Disposal on Human Health and its management in Serrekunda market municipality.

Table 1. Responses.

\begin{tabular}{|c|c|c|c|c|c|c|c|c|c|c|c|c|c|}
\hline No. & Statement & $\mathrm{Sa}$ & $\begin{array}{c}\text { SA } \\
\%\end{array}$ & A & $\begin{array}{l}\mathrm{A} \\
\%\end{array}$ & SD & $\begin{array}{l}\text { SD } \\
\%\end{array}$ & D & $\begin{array}{l}\mathrm{D} \\
\%\end{array}$ & $\frac{\mathrm{SA}+\mathrm{A}}{2}$ & $\begin{array}{c}\mathrm{SA}+\mathrm{A} \\
\begin{array}{c}2 \\
\%\end{array}\end{array}$ & $\frac{S D+D}{2}$ & $\begin{array}{c}\mathrm{SD}+\mathrm{D} \\
2 \\
\%\end{array}$ \\
\hline 1 & $\begin{array}{l}\text { I know how to protect myself against } \\
\text { any hazards of waste disposal. }\end{array}$ & 48 & 21.8 & 17 & 7.7 & 90 & 65 & 65 & 29.6 & 32.5 & 14.8 & 77.5 & 21.9 \\
\hline 2 & $\begin{array}{l}\text { I am capable of taking recommended } \\
\text { protective measures when necessary. }\end{array}$ & 32 & 14.6 & 105 & 47.7 & 27 & 12.3 & 56 & 25.5 & 68.5 & 31.2 & 42 & 18.9 \\
\hline 3 & $\begin{array}{l}\text { Nobody in this area have being } \\
\text { hospitalized due to any of the illness } \\
\text { associated with improper waste } \\
\text { disposal. }\end{array}$ & 33 & 15 & 61 & 27.7 & 89 & 40.5 & 37 & 16.8 & 47 & 21.4 & 63 & 28.7 \\
\hline 4 & $\begin{array}{l}\text { I do not think that any of those } \\
\text { hazards associated with improper } \\
\text { waste disposal and management } \\
\text { can affect me. }\end{array}$ & 82 & 37.3 & 22 & 10 & 41 & 18.6 & 75 & 34.1 & 52 & 23.7 & 58 & 26.4 \\
\hline 5 & $\begin{array}{c}\text { I know how to treat myself affected } \\
\text { if affected with waste disposal } \\
\text { vulnerability. }\end{array}$ & 102 & 46.4 & 63 & 28.6 & 13 & 5.9 & 42 & 19.1 & 82.5 & 37.5 & 27 & 12.5 \\
\hline 6 & $\begin{array}{c}\text { If affected with waste disposal } \\
\text { improper management threats and } \\
\text { severity, I know where to treat myself. }\end{array}$ & 99 & 45 & 82 & 37.3 & 24 & 10.9 & 15 & 6.8 & 90.5 & 41.2 & 19.5 & 8.9 \\
\hline 7 & $\begin{array}{l}\text { If affected with self-efficacy, } \\
\text { I know when to treat myself. }\end{array}$ & 110 & 50 & 52 & 23.6 & 38 & 17.3 & 20 & 9.1 & 81 & 36.8 & 29 & 13.2 \\
\hline 8 & $\begin{array}{l}\text { I am aware that staying close to waste } \\
\text { dumpsite, I am exposing myself to } \\
\text { respiratory threat diseases such as } \\
\text { Asthma, Tuberculosis, Tuberous } \\
\text { Sclerosis, pulmonary Hypertension, } \\
\text { Lung Cancer etc. }\end{array}$ & 38 & 17.3 & 21 & 9.6 & 73 & 33.2 & 38 & 17.3 & 29.5 & 13.5 & 80.5 & 25.3 \\
\hline 9 & $\begin{array}{l}\text { I am aware that staying close } \\
\text { dumpsite, I am exposing myself } \\
\text { to liver dysfunction. }\end{array}$ & 62 & 28.2 & 43 & 19.6 & 97 & 44.1 & 18 & 8.2 & 52.5 & 23.9 & 57.5 & 26.2 \\
\hline 10 & $\begin{array}{l}\text { I am aware that improper handling of } \\
\text { wastes causes skin disease such as } \\
\text { skin irritation. }\end{array}$ & 76 & 34.6 & 18 & 8.2 & 101 & 45.9 & 25 & 11.4 & 47 & 21.4 & 63 & 28.7 \\
\hline
\end{tabular}




\section{Continued}

Are you aware that waste that releases dioxins pose health risk when diffuses

11 into the air (atmosphere) and we breathe them in through our nostril and lungs.

I am aware that waste disposal

12 workers at market municipality are at a greater risk.

89

have what it takes to prevent myself from being affected.

$11 \quad 53.6 \quad 36$

$16.4 \quad 11.4 \quad 25$

$41-18.6$

77

2.7

$83 \quad 37$

27

5 at commercial center/market municipality will be affected by waste disposal

Are aware that improper disposal of waste can significantly affect the population of people living close to market dumpsite.

I am aware that staying close to waste dumpsite I am exposing myself to offensive odour

I am not aware that exposure to

17 improperly handled waste can affect human growth.

I am aware that human blood can be infected if exposed to waste.

109

49.6

49.6

12

No health hazards associated with improper waste disposal has ever affected anybody in the market municipality.

I am not aware that minimizing

20 e-waste helps to reduce the amount of energy we take from the earth.

21 I am aware that waste can be recycled and reuse for another useful product.

I have all the protective materials to protect myself from being infected.

I am capable of avoiding improper

23 waste disposal that may affect my health in the market area.

24 I am not aware that improper waste disposal causes neurological disorder.

25 I am not aware that incineration is a means of waste management.

103

$61-27.7$

72

$59 \quad 26.8$

$17 \quad 7.7$

88

101

45.9

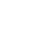

13.2

91

$20.5 \quad 65$

29.4

14.6

50

$14.6 \quad 43$

19.6

86

39.1

45.5

20.7

29.4

27

12.3

$35.9 \quad 97$

44.1

22

1

88

40

$88 \quad 40$

93

$5.5 \quad 27$

$12.3 \quad 90.5$

41.2

19.5 


\subsection{Test of Hypothesis}

Null Hypothesis $\left(\mathrm{H}_{\mathrm{o}}\right)$ : There is no significant difference between perceived vulnerability of residents in Serrekunda market municipality waste disposal management.

Using t-test, at 0.05 level of significance at degree of freedom (d f), 24 in two tails, the Critical value (Tabulated value) and calculated value is compared and conclusion is drawn, calculated $t$-test value is written as $\left(t_{c a l}\right)$.

That is,

$$
\begin{gathered}
\mathrm{t}_{\text {cal }}=0.64 \\
\mathrm{t}_{0.05(2)} 24=2.064
\end{gathered}
$$

Since the calculated value 0.64 is slightly less than the critical (tabulated) value 2.064, Null Hypothesis $\left(\mathrm{H}_{\mathrm{O}}\right)$ is therefore accepted at $(\mathrm{P}>0.05)$ with slight difference, under non-parametric condition.

It can therefore, be concluded that there is no significant difference in the market waste municipality level of management from the responses of the respondents $(\mathrm{P}>0.05)$, that is the calculated $\mathrm{t}$-value is slightly close to the tabulated $\mathrm{t}$-value $(0.64 \neq 2.064)$ with a close difference of 1.42 which makes it insignificant.

\section{Discussion}

In the table above, item 1 and 2, from the data collected from the respondents, the analysis showed on the awareness of how one can protect oneself against any hazard of waste in the market municipality, an average number of 32.5 and 68.5 represents an average percent of $14.8 \%$ and $31.2 \%$ of agreed response and I am capable of taking recommended protective measures when necessary compared to disagree average percent of response of $35.3 \%$ and $18.9 \%$. The percentage of $54.2 \%$ disagreed of respondents was recorded higher than the agreed percent response of $46 \%$. This was similar with the work done in Robe town, in Ethiopia by United Nation (2014). With regards to awareness, households do not have awareness training methods on how to handle solid wastes, this makes them not to be satisfied with the current condition of municipal solid waste management.

Item 3 and 4 from the table showed an average agreed response value of 47 , representing $21.4 \%$ of nobody in this area has been hospitalized due to any of the illness associated with improper disposal of waste against disagreeing response of $28.7 \%$ while item 4 showed mean response of 52 agreed with $23.7 \%$ while the disagree response was $26.4 \%$ on I do not think that any of those hazards associated with waste disposal can affect me. The average percent of agreed is less than that of disagreed from respondents response.

Item 5 and 6 had mean population response and percentage value of $82.5 \%$, $37.5 \%$ agreed on if affected, I know how to treat myself and if affected, I know where to treat myself. The population response of mean agreed 90.5 with a percentage average of $41.2 \%$ against disagreed response of $12.5 \%$ and $8.9 \%$ respectively. The agreed percentage value in item $5 \& 6$ is higher than that of disagreed. 
Both responses of the respondents in the Serrekunda market municipality waste disposal were not satisfied, because is not that treats themselves that survived it especially with carcinogenicity effects.

Item 7 and 8 , in Table 1, had 81 respondents representing average percentage rate value of $36.8 \%$ agreed, 29 respondents representing average disagree percentage rate of $13.2 \%$ on if affected, I knew when to treat myself. Item number 8 in Table 1, showed 29.5 respondents, $13.5 \%$ of agreed that I am aware that staying close to dumpsite, I am exposing myself to respiratory track diseases such as asthma, sclerosis with disagree response of $36.5 \%$. Study had shown a similar work done that had high percent according to Cheru (2010) [10] which revealed that, Dassie town in Ethiopia, about $76 \%$ of solid waste produced in the city, was not disposed accordingly and this will bring about different health challenges. This study showed that above 55\% respondents; discard solid wastes illegally into the environment most especially in market area. The marketers and the council lacked attitudinal innovation commitment and environmental sanitization.

Item 9, 10, 11 and 12 showed the total respondents average percent population of agreed rates of $23.9 \%, 21.4 \%, 35 \%$ and $37.8 \%$ respectively on the awareness of staying close to disposal dumpsite in market waste municipality and management, I am exposing myself to liver dysfunction, difficulties in breathing, skin irritation and greater risk against disagreed average percentage rate of $26.2 \%$, $28.7 \%, 15 \%$ and $12.3 \%$ respectively. Most respiratory health challenges people faced around the Serrekunda market Centre is due to the de-channelization and blocking of drainage system by the marketers and Serrekunda residents. This forced running water in the form of sewerage flood to make the whole market environment to be flooded with, as well as polluting the air, water and soil. The combination of these affects the inspiration of the market environment in the town which also poses problems and health challenges.

Item 13 and 14 shows the population of respondents for both agreed and disagreed responses, the average percentage rate of $20.7 \%$ and $28.7 \%$. Disagree average percentage rate of $29.3 \%, 21.45 \%$ with total respondents population of respectively. This study shows that in Serrekunda market, $49.2 \%$ of marketers are not satisfied with the solid waste disposal management and $50.8 \%$ of households are dissatisfied with the recent state of municipal solid waste management (MSWM) practice in Serrekunda commercial center.

Item 15 and 16 in Table 1, shows some significant variation in the respondents responses in the average population rate of agreed response as well as disagreed mean responses on I have what it takes to prevent myself from being affected, am I aware that staying close to waste dumpsite, I am prone to exposing myself to offensive odor that causes air pollution. The percentage rates of agreed and disagree averages are $25 \%$ for agreed and $25 \%$ for disagreed; both are insignificant and $41.2 \%$ and $8.9 \%$ with a significant difference.

Item 17 and 18, a population respondents of 43 representing average percen- 
tage rate of $19.6 \%$ for agreed, and population of 67 respondents had percentage rate of $30.5 \%$ respectively for average disagreed rate. Furthermore, a total population of 31.5 responses and an average percentage mean agreed of $14.3 \%$ against $35.7 \%$. There is a significant difference in both population response and the percentage rates of both items, the percentage rate of disagreed is recorded higher than that of agreed as shown above. This implies that the improper way of waste disposal is deteriorating the Environment.

Item 19, 20, 21 and 22 respondents population and average percentage rates for agreed and disagreed are as follows $46.4 \%, 20.5 \%, 23.75 \%$ and $41.2 \%$ against disagreed average rate of $3.7 \%, 29.4 \%, 26.4 \%$, and $8.9 \%$ respectively. Both average agreed and disagreed rates showed significant difference in their comparison, the agreed average percentage rate of item 19 is higher than the disagreed percentage rate. In item 20 and 21, the agreed average percentage rate was recorded lower than disagreed percentage rate respectively, and item 22 agreed average percentage rate recorded higher than that of disagree. The percentage increase rate may be due to open dumped waste.

Item 23,24 , and 25 are for respondents' total population responses and percentage rates for mean values of both agreed and disagreed. The average rate of agreed is $20.7 \%, 10 \%, 41.2 \%$ respectively against disagreed average rate of $29.4 \%$, $40 \%$, and $8.9 \%$ respectively. There is a significant difference as disagreed percentage rate recorded the lowest while the highest was observed in the average agreed rate; we had $40.2 \%$ as shown below. Both items $23 \& 24$ recorded lower percentage rate of agreed against disagreed, but item 25 recorded average rate of agreed higher than disagreed.

\section{Summary}

Summarily, this research has made me expose other related environmental departments in the country that their objective is just theoretical and paper work without focusing on the sustainability of the people and the healthy environment for future generation to come, to the Gambia government; this is because the country is for all of us. The study is only centered on market and the respondents' response that looks like this, sincerely speaking, if opportunity and time frame is given to focus on all the commercial centers in the country, the next ten years ( $10 \mathrm{yrs}$ ) to come. That is by 2040 , this country will turn into a sinkhole because of different environmental pollution that is generated daily in the market centers. Generally, at the biochemical level of improper waste disposal management, the toxic effects of waste caused by excess concentration of heavy metal include sites competition with essential metabolite, replacement of essential ions, damage to cell membrane and reaction with phosphate groups [11]. It is recommended that awareness on the dangers of using waste dumpsites as a site for selling water, edible fruits and vegetables, should be discontinued in order to avert the health effects of consuming crops sold in the market place that are contaminated with heavy metals. 


\section{Recommendations}

Base on this research finding, the following recommendations are considered:

1) Low waste generation and proper management of waste disposal, minimize the environmental pollution, and ecofriendly environment is achieved.

2) Phytoremediation in the dumpsite and non-dumpsite act as a new age of environmental waste disposal management that will bring and encourage sustainable waste management.

3) Government should also encourage every individual living in the Gambia on the benefits of planting trees which bring about Green Belt Movement (GBM) that also help in reduction of gaseous substances that causes climate change and global warming.

4) Modern renewable waste disposal strategy should also be embarked and adopted.

5) Sustainable waste disposal and management should be practiced among all individuals in order to heal the Earth from emission.

\section{Conclusion}

Conclusively, awareness should be given to the public and marketers. This study also showed that all the physical, chemical and biological parameters generated from this waste dumped in the market municipality, and in the Gambia, showed that there is no proper care and hygiene environment as recommended by combined team of environmental and public health officers compared to World Health Organization acceptable standard.

\section{Acknowledgements}

I acknowledged School in Agriculture \& Environmental Sciences, other staff in the University of The Gambia (UTG) for their support in one way or the other. I also acknowledged my statistical mentor, Professor T.O.T. Imoobe, other lecturers and students in the Department of Animal and Environmental Biology who in one way or the other contributed to facilitating the completion of this work.

\section{Funding}

There is no funding or grant by any organization or funding agency both in not-for-profit, profit or the public for this study.

\section{Availability of Data and Materials}

The data used to support the findings of this study are available upon request from the authors.

\section{Authors' Contributions}

All authors made substantial contributions to conception and design, acquisition of data, or analysis and interpretation of data; took part in drafting the article or revising it critically for important intellectual content; agreed to submit to the 
current journal; gave final approval of the version to be published; and agree to be accountable for all aspects of the work.

\section{Conflicts of Interest}

The authors declare no conflicts of interest.

\section{References}

[1] United Nations (2014) World Urbanization Prospects. United Nations, New York.

[2] Ma, J. and Hipel, K.W. (2016) Exploring Social Dimensions of Municipal Solid Waste Management around the Globe-A Systematic Literature Review. Waste Management, 56, 3-12. https://doi.org/10.1016/j.wasman.2016.06.041

[3] Rathje, W.L. (2001) Rubbish Wash and the Archaeology of Garbage. University of Arizona Press, United State of America, 978, 8165-8190.

[4] Ogbodo, S.G. (2010) Handbook on National Environmental Standards and Regulations Enforcement Agency Act. Law Research and Development, Ambik Press, Lagos, 1080-1082.

[5] Rogers, R.W. (1983) Cognitive and Physiological Processes in Fear Appeals and Attitude Change: A Revised Theory of Protection Motivation. In Cacioppo, J. and Petty, R., Eds., Social Psychophysiology, Guilford Press, New York, 153-177.

[6] Rogers, C. (2016) The Critical Need for Human Disaster Response Plans. Journal of Business Continuity and Emergency Planning, 9, 262-371.

[7] Milne, S., Sheeran, P. and Orbell, S. (2000) Prediction and Intervention in Health-Related Behavior: A Metal-Analytic Review of Protection Motivation Theory. Journal of Applied Social Psychology, 30, 106-143. https://doi.org/10.1111/j.1559-1816.2000.tb02308.x

[8] Nachmais, D. and Frankfort-Nachmais, C. (2008) Research Method in Social Sciences. http://store.vitals.source.com/

[9] Ogbeibu, A.E, (2014) A Practical Approached to Research and Data Handing. Mindex Co Ltd., Benin-City, 74-85.

[10] Cheru, S. (2010) Assessment of Solid Waste Management in Dassie Town. MA Thesis, Addis Ababa University, Ethiopia.

[11] Alloway, B.J. and Ayres, D.C. (1997) Chemical Principles of Environmental Pollution, 2nd Edition, Black Academic and Professional Publication, London, Wienheim, New York, Tokyo, Melbourne, Madras, 190-217. 